\title{
A educação jurídica para além da crítica: Elementos para uma ação docente contra-ideológica
}

\section{The legal education beyond criticism: Elements for a counter-ideological teaching action}

\author{
Luís Henrique Orio \\ Mestrando na área de Teoria, Filosofia e História do Direito pela UFSC \\ luishenrique.1ho@gmail.com
}

\begin{abstract}
Resumo: O presente artigo se dedica a formular uma compreensão da atual conjuntura da educação jurídica na realidade brasileira e sua reconfiguração na formação de uma respectiva força de trabalho e conformação da hegemonia, relacionando tal análise ao modelo de educação superior no Brasil e os imperativos do capital e do mercado do ensino do Direito. Situada a conjuntura, apresenta-se uma caracterização da crítica do ensino do Direito, e os fatores que trazem consigo bloqueios a possíveis intervenções concretas nestes âmbitos que sejam vinculadas organicamente à classe trabalhadora e movimentos sociais no Brasil; fatores aqueles que vêm no esteio da ideologia do fim da história, do giro pós-moderno das ciências sociais e do descenso da luta de classes. Coloca-se fundamentalmente a necessidade de retomar a contundência da crítica acompanhada da superação da mera negação estéril da educação jurídica, afirmando-se a possibilidade de e alguns elementos para uma ação docente orgânica contra-ideológica.
\end{abstract}

Palavras-Chave: Educação jurídica. Educação superior. Ação docente. Crítica. Ideologia.

\begin{abstract}
This paper is dedicated to develop an understanding of the current state of legal education in the Brazilian reality and its reconfiguration in the formation of their respective labor force and conformation of hegemony, relating this analysis to the higher education model in Brazil and the imperatives of capital and the legal education market. Situated the context, we present a characterization of the critical perspective of teaching law, and the factors which bring with them concrete locks to potential concrete interventions in these areas that are organically linked to the working class and social movements in Brazil; those factors that come in the track of the end of history ideology, the postmodern turning of social sciences and the descent of class struggle. We basically point the need to retake the forcefulness of the critical followed to the overcoming of the simple sterile denial of legal education, asserting the possibility of and some elements to an organic counter-ideological teaching action.
\end{abstract}

Key-words: Legal education. Higher education. Teacher action. Critical. Ideology.

Originais recebidos em: 22/03/2014

Aceito para publicação em: 16/05/2014

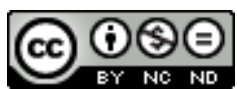
Comercial-Vedada a criação de obras derivadas 3.0 Unported License. 


\section{Introdução}

A reflexão sobre o sentido de uma ação docente no âmbito da educação jurídica que seja comprometida com a transformação da realidade implica em uma primeira avaliação: a possibilidade de uma práxis de tal caráter em um espaço que se presta precipuamente ao contrário. Ou seja: a dedicação em encampar uma perspectiva radicalmente diferente não mereceria ser resguardada para outro campo mais profícuo ao seu desenvolvimento teórico-prático?

Mesmo que à primeira vista uma resposta nos marcos do marxismo ou da mera análise sócio histórica dos limites e bloqueios inatos à educação jurídica apontaria seu baixíssimo e quiçá nulo potencial de determinação de qualquer alteração significativa na realidade concreta da educação, do Direito e da sociedade brasileira, e muito embora estas ponderações em muito já foram enfrentadas e respondidas contundentemente por autores da robustez de um Roberto Lyra Filho (1993), por exemplo, elas são trazidas neste artigo como reenfrentamento dialético necessário das contradições, possibilidades e sucedâneos éticos de tal perspectiva docente na educação jurídica.

Posta a perspectiva do artigo, entende-se não ser possível compreender a educação jurídica e seu papel hoje no Brasil de maneira descolada da conjuntura da educação superior como um todo, elemento que primeiro se tentará caracterizar para o posterior enfrentamento das nuances históricas da educação jurídica desde a criação dos primeiros cursos de direito no Brasil até o complexo cenário atual.

$\mathrm{Na}$ sequência, dados os limites do presente artigo e a complexidade de enfrentamento de elementos objetivos para se promover uma espécie de balanço da vasta produção da crítica ao longo das últimas décadas, far-se-á uma tentativa de relacionar os entraves para o fortalecimento e vigor de correntes e intervenções críticas no ensino do Direito a fatores estruturais, políticos e sociais.

Entendendo que as dificuldades estruturais e conjunturais de uma intervenção prática organicamente vinculada à classe trabalhadora no âmbito da educação jurídica podem conduzir a crítica a uma mera negação de seu real papel na sociedade e o abandono da perspectiva de intervenção concreta alternativa neste espaço, faz-se o esforço de retrabalhar elementos que dizem com a necessidade e a possibilidade de uma ação docente dita contra-ideológica no ensino do Direito. 


\section{Breve esboço da conjuntura da educação superior no Brasil}

Analisar os caminhos historicamente recentes da educação superior no Brasil é tarefa um tanto inglória: confrontar politicamente a hegemonia do consenso estabelecida pós-governo Lula da Silva (2003), que implica dizer em resumo que pouco ou nada de substancialmente diferente foi feito em relação aos governos anteriores neste setor, é atrair para si um falso lugar numa falsa polarização que as evidências insistem em desmentir.

Muito embora uma análise com este conteúdo não prescinda de uma confrontação socialmente determinada de um complexo e ainda não totalmente compreendido programa de governabilidade que notoriamente vem ruindo aos poucos (não é precipitado dizer que os fenômenos de junho de 2013 apontam para isso), as limitações da proposta do presente trabalho implicam concentrar a abordagem na caracterização das atuais políticas para a educação superior no Brasil, a partir do seu aclaramento já bastante realizado por intelectuais e movimentos sociais ligados à educação.

Assim que um elemento central para tal análise é o considerável atrelamento das políticas educacionais no Brasil às orientações de organismos internacionais que, aliadas à conformação de uma abertura de mercado aos interesses internos, logrou aperfeiçoar o atual quadro da educação superior, que assume assim um traço marcadamente mercantilista.

Esta preocupação recente de organismos internacionais com a educação (notadamente a partir do documento La enseñanza superior: las lecciones derivadas de la experiencia, de 1995 do Banco Mundial) reflete a reorganização produtiva do capital internacionalmente. Enquanto que em meados da década de 1970 estes organismos dedicavam-se a formular e orientar políticas de controle de pobreza, com a ilusão do apaziguamento de desigualdades em territórios compreendidos como "propensos ao comunismo", as referidas novas formas de imperialismo imprimiram também um giro nas ações destes sujeitos, que passaram a colocar a educação como elemento central de seus discursos (LEHER, 1999).

Barreto e Leher (2008, p. 431), no trabalho em que produzem uma análise de discurso dos documentos do Banco Mundial sobre a educação, apresentam o conjunto 
de pequenas reformas e processos de "assimilação" daquelas referidas orientações nos marcos regulatórios brasileiros:

De fato, os marcos normativos mais amplos que vêm reconfigurando a educação superior brasileira são fortemente congruentes com os documentos do banco apontados anteriormente. A primeira geração compreende o período de "reformas" da Constituição Federal brasileira, em particular: a emenda constitucional n. 19, de 4 de julho de 1998, que dispõe sobre a reforma administrativa (parte estrutural da reforma do Estado), modificando também o inciso V do art. 206, e a proposta de emenda constitucional n. 370, que pretendeu alterar o estatuto da autonomia universitária, deslocando-a para o nível infraconstitucional. Parte dos objetivos bancomundialistas já fora obtida na própria Constituição de 1988, em especial no art. 209 (“o ensino é livre à iniciativa privada"), por ação de uma burguesia de serviços em ascensão. A segunda geração corresponde ao processo de elaboração da nova Lei de Diretrizes e Bases da Educação Nacional (LDB, lei n. 9.394/96) e do Plano Nacional de Educação (PNE, lei n. 10.172/01), dispositivos que decididamente incentivam a diferenciação das instituições de ensino superior e abrem caminho para a proliferação de cursos à distância. Finalmente, a terceira geração corresponde a um complexo de medidas que articula avaliação, diretrizes curriculares, competências, empregabilidade, inovação tecnológica, TIC, sociedade da informação/ conhecimento etc., operando a comodificação da educação de modo orgânico com o padrão de acumulação que prevaleceu no país.

Neste sentido, a educação é relegada à lógica de mercadoria (commodity) - que é concepção nuclear da agenda do Banco Mundial -, circunstância que no contexto brasileiro tanto logra atrelá-lo a este modelo de conhecimento globalizado e também atende às contingências de demanda de força de trabalho de setores dominantes da burguesia local (financeiro, agronegócio e de exportação de commodities), além de implicar numa significativa abertura de mercado para investimentos do capital interno (BARRETO E LEHER, 2008).

Este amálgama de interesses internos e externos determinantes do modelo de educação superior no Brasil repercutiram em uma evolução constante nos últimos anos: o vertiginoso crescimento do setor privado ${ }^{1}$, impulsionado já durante o governo FHC (1995-2002) e seguido no governo Lula da Silva (2003-2010), com um traço distintivo que também é constitutivo desta nova hegemonia de coalisão, qual seja, o aporte de recursos públicos a este setor privado através do Programa ProUni, que funciona como uma espécie de compra de vagas para uma parte da população mais carente. Injeta-se recursos no capital privado e cria-se a falsa impressão de um atendimento de demandas por políticas afirmativas (MATTOS, 2009).

No setor público, foi no governo Lula que se verificou, principalmente a partir do REUNI (Decreto $n^{\circ} 6.096$ de 2007) a criação de novas universidades e uma

\footnotetext{
${ }^{1}$ Conforme dados do último Censo da Educação Superior de 2011.
}

Em Debat: Rev. Dig., ISSNe 1980-3532, Florianópolis, n. 10, p. 19-34, jul-dez, 2013. 
expansão abrupta de vagas nas instituições federais de ensino. As posteriores greves de estudantes e trabalhadores federais da educação viriam a denunciar os efeitos do REUNI nas instituições: com uma expansão desordenada e exclusivamente quantitativa, a relação professor $\mathrm{x}$ aluno se dilatou, com a consequente precarização do trabalho docente; sem a respectiva expansão estrutural, as condições de ensino/aprendizagem restaram prejudicadas, consagrando ao fundo um modelo de formação aligeirada e simplificada ${ }^{2}$.

Neste modelo comoditista de educação superior sobressai nitidamente o desmantelamento do modelo tradicional de universidade, calcado na indissociabilidade entre ensino, pesquisa e extensão, para sua conversão institucional em um polo de oferta de ensino, enquanto que as atividades de pesquisa são impulsionadas em alguns poucos centros de excelência. A organização do suporte e financiamento das atividades de pesquisa, por sua vez, se mostra eminentemente produtivista, reproduzindo a lógica do capital no sentido de direcionar o repasse de recursos tanto maiores sejam a produção e o status avaliativo prévio, o que implica no fortalecimento de espaços de excelência e precarização de espaços em construção.

Estabelecido este quadro, vê-se que, se com Gramsci (1989) já era possível compreender o movimento de aformoseamento das instituições educacionais para o atendimento das necessidades de formação da classe trabalhadora, ao contrário da formação tradicional "humanista" destinada a intelectualidade orgânica dominante, a complexificação das relações sociais sob o influxo das reestruturações e adequações produtivas do capital e do imperialismo nas sociedades periféricas logrou imprimir aos sistemas educacionais uma tarefa também centralmente hegemônica e de internalização de valores.

Entrementes, se na condensação de políticas neoliberais com medidas sociais focalizadas, algo próximo ao neoliberalismo de terceira-via (MATTOS, 2009), viu-se que a educação superior remodelada recentemente no Brasil se articula na perspectiva de uma consolidação do consenso entre capital (um mercado próprio no setor e demandas de formação de força de trabalho, principalmente) e classe trabalhadora (pela ilusão do acesso), também é imperioso alocar a educação superior enquanto educação formal num movimento mais amplo de reafirmação ideológica, como adverte Mészáros (2008, p. 44): 
Aqui a questão crucial, sob o domínio do capital, é assegurar que cada indivíduo adote como suas próprias as metas de reprodução objetivamente possíveis do sistema. Em outras palavras, no sentido verdadeiramente amplo do termo educação, trata-se de uma questão de "internalização" pelos indivíduos - tal como indicado no segundo parágrafo desta seção - da legitimidade da posição que lhes foi atribuída na hierarquia social, juntamente com suas expectativas "adequadas" e as formas de conduta "certas", mais ou menos explicitamente estipulas neste terreno. [...]

As instituições formais de educação certamente são uma parte importante do sistema global de internalização. Mas apenas uma parte. Quer os indivíduos participem ou não - por mais ou menos tempo, mas sempre em um número de anos bastante limitado - das instituições formais de educação, eles devem ser induzidos a uma aceitação ativa (mais ou menos resignada) dos princípios reprodutivos orientadores dominantes na própria sociedade, adequados a sua posição na ordem social, e de acordo com as tarefas reprodutivas que que lhes forem atribuídas.

Este último elemento posto em evidência na citação constitui aspecto central da compreensão da intencionalidade da educação formal para o funcionamento do sóciometabolismo do capital e sua conservação. De forma que concentrar a análise da educação superior em sua atual conjuntura e apontar criticamente seu projeto em evidência não implica um esquecimento conveniente da problemática em torno daquelas suas características de certa forma inatas a um determinado modo de produção, algo já bastante acumulado e debatido pela própria bibliografia cá retomada. Ao contrário, escarafunchar o modelo de educação em processo de implementação traduz precisamente a necessidade de acompanhar dialeticamente os seus aformoseamentos em relação às nuances da organização material da vida social.

Resta, portanto, a tentativa de formular timidamente uma compreensão da educação jurídica que possa minimamente ser conectada ao modelo geral de educação superior brasileiro e às suas referidas contingências.

\section{A educação jurídica do bacharelismo à produção em série}

A caracterização da educação superior brasileira realizada no tópico acima por si só já apresenta elementos bastante descritivos da educação jurídica em específico. Por certo não é possível considerar a formação jurídica autonomamente, de modo que as determinações centrais do modelo de educação superior em vigência lhe são igualmente aplicáveis.

Ocorre que a formatação histórica da educação jurídica no Brasil possui algumas nuances que refletiram muito da organização sócio-política brasileira desde o século 
XIX até o presente tempo histórico e que de certa forma constituem um acúmulo bastante presente no que se entende por "cultura jurídica" brasileira.

A funcionalidade original da educação jurídica no Brasil, com a criação (1827) e instalação (1828) dos primeiros cursos de Direito, em São Paulo e Olinda, residia na necessidade de formação de uma elite intelectual que pudesse ocupar os cargos da institucionalidade própria que se criava após a independência (1822) perante a metrópole portuguesa (RODRIGUES, 2005).

O estado-nação independente, encampando a retórica e as formas liberais burguesas, demandava para sua consolidação e para bem atender a intencionalidade das elites locais agora desgarradas da ingerência da metrópole, a existência de um

[...] pólo de sistematização e irradiação do liberalismo enquanto nova ideologia político-jurídica capaz de defender e integrar a sociedade; [e que pudesse] dar efetivação institucional ao liberalismo no contexto formador de um quadro administrativo-profissional. (WOLKMER, 2003, p. 67/68).

A partir da narrativa histórica exposta por Rodrigues (2005), pode-se visualizar a sequência evolutiva da educação jurídica no Brasil desde sua fundação nos seguintes traços:

- Império: as faculdades eram controladas pelo governo central; o paradigma predominante era o do jusnaturalismo (já em 1870 começaria o influxo do positivismo comtiano); o ensino/aprendizado seguia o estilo coimbrão (aulasconferência);

- Transição à República: abriu-se a possibilidade de criação de cursos privados; começam a surgir cursos em outras cidades do território brasileiro;

- República Velha: consolidação do paradigma positivista; giro dos currículos para uma formação mais acentuadamente profissionalizante;

- 1930-1972: em 1931 os cursos se reestruturam em bacharelado e doutorado (o primeiro com um perfil mais profissionalizante e o segundo destinado a estudos de alta cultura); em 1962 é estabelecido o currículo mínimo nacional para os cursos de Direito; nesta época começa mais nitidamente a proliferação de cursos e faculdades;

- 1972 - hoje: em 1972 formula-se um novo currículo mínimo; acentua-se um crescimento já desordenado dos cursos de Direito; em 1996 é promulgada a Lei de Diretrizes e Bases da Educação; a gestão e regulação da educação jurídica passa ser mais ampliada, compreendendo as intervenções da Ordem dos Advogados do Brasil e Associação Brasileira do Ensino do Direito, por exemplo. 
Evoluindo para uma caracterização mais recente da educação jurídica no Brasil depara-se com informações que indicam existirem aqui mais cursos de Direito do que em todos os demais países do mundo juntos e que o contingente de bacharéis formados na área aproxima-se de quatro milhões ${ }^{3}$. Ou seja: uma produção em série.

A circunstância de um curso de Direito demandar menores investimentos estrutural e de pessoal e o status que historicamente é conferido pelo senso comum aos profissionais da área são elementos que, conjugados às políticas de abertura da educação a iniciativa privada executadas acentuadamente nas últimas duas décadas possibilitam compreender este inchaço de estudantes e egressos e a proliferação de cursos.

A lógica mercantil, portanto, se repete: formação aligeirada, acentuadamente profissionalizante e descolada de pesquisa e extensão. A força de trabalho que daí deriva é direcionada majoritariamente para setores da burocracia estatal ou para a proletarização (praticamente em regime de superexploração) em escritórios e corporações, ao passo que os altos cargos do Judiciário continuam sendo ocupados de acordo com um recorte de classe.

Dada a centralidade do espaço do Direito na legitimação superestrutural da ordem burguesa, é certo que o espaço de formação de seus operadores demanda uma autorreferenciação e um enclausuramento epistêmico e ideológico um tanto mais rígido à dialética da luta de classes, de modo que nele se vislumbra, praticamente inalterável desde sua formação, uma estrutura de base axiológica calcada no paradigma ideológico do liberalismo, com nuances de conservadorismo, e no paradigma epistemológico do positivismo (RODRIGUES, 2005).

Não está colocada como perspectiva desta pequena contribuição o desvelamento da essência das intricadas relações e mútuas determinações entre o modelo de educação jurídica, o mercado de oferta de cursos de Direito, o cada vez maior mercado de cursinhos jurídicos preparatórios para concursos, a maneira como estes últimos são organizados e o Exame da $\mathrm{OAB}$, mas não soa inconsequente a afirmação de que a educação jurídica no Brasil, em sua essência, transfigura-se (ou, melhor, se reafirma) de

3 As referidas informações são de 2010 e foram noticiadas pelo Conselho Nacional de Justiça, por intermédio de um de seus conselheiros, podendo ser acessada na reprodução que se encontra em $<$ http://www.oab.org.br/noticia/20734/brasil-sozinho-tem-mais-faculdades-de-direito-que-todos-ospaises $>$

Em Debat: Rev. Dig., ISSNe 1980-3532, Florianópolis, n. 10, p. 19-34, jul-dez, 2013. 
um espaço de produção de conhecimento para um grande balcão de negócios, no qual as mediações da ideologia (para o que aqui é trabalhado) são centralmente determinantes.

\section{A crítica nas (e) suas amarras}

A educação jurídica assim caracterizada, contudo, não deixou de receber em seu seio o enfrentamento de valorosas contribuições teórico-práticas de denúncia de seu caráter formalista/tecnicista/mercadológico/ideológico e de construções alternativas contra majoritárias.

Adstritamente à tradição crítica jurídica brasileira ${ }^{4}$, que entrecruza obviamente com as atuações em face da educação jurídica, floresceram o movimento do Direito Alternativo, o Pluralismo Jurídico, o Direito Achado na Rua, o Direito Insurgente, foi criada a Rede Nacional de Advogadas e Advogados Populares (RENAP) e várias Assessorias Jurídicas Populares em diversas instituições de ensino superior no Brasil, além das atuações da Federação Nacional de Estudantes de Direito (FENED) e da Associação Brasileira do Ensino do Direito (ABEDi).

Como já alertado na introdução, a proposta não é de fazer um balanço dos logros das experiências das teorias e práticas críticas para a educação jurídica, mas tão somente compreender as possibilidades, desafios e possíveis desvios para a retomada/fortalecimento/formulação de teorias críticas do direito e da educação jurídica hoje.

Tome-se um primeiro elemento de ordem metodológica que projeta desde já a preocupação central trabalhada no artigo: a dinâmica da luta de classes, mais do que qualquer instigação acadêmica, é o elemento-chave para compreensão do surgimento e desparecimento de teorias críticas do Direito (em se partindo da concepção dialética de Lyra Filho, 1980). Neste sentido, apenas a vinculação orgânica nesta relação fundante da sociedade pode preencher de sentido a dedicação de, pelo menos, refrear a lógica alienante da educação jurídica.

De modo que a força da reprodução hegemônica da ideologia que conduz a introspecção da educação como acesso a um elemento de adequação e conformação aos lugares previstos e possíveis de se ocupar na sociedade atribui à crítica (principalmente

4 Omite-se aqui as notáveis correntes latino-americanas e europeias por mera contingência, já que suas experiências foram bastante ricas e profusas. 
marxista) deste mesmo mecanismo de assimilação a pecha do atraso, o lugar das utopias mortas e enterradas que não mais condizem com um ilusório tempo histórico no qual a tarefa é preservar o insuperável, é contornar os microproblemas sociais eventualmente existentes com base no que a inclusão e aperfeiçoamento desta sociedade do conhecimento tem a oferecer, aí incluídos o acesso, as leis, a responsabilidade social, etc ${ }^{5}$.

Ciceroneiam esta decretação do fim da história, além dos paradigmas majoritários positivista e liberal, correntes das ciências sociais bastante em voga, como as teorias do fim da sociedade do trabalho (André Gorz e o próprio Habermas, v.g.) e as teorias da pós-modernidade (Boaventura de Sousa Santos ${ }^{6}$ e Jean-François Lyotard, v.g.), que, muito embora se postulem - e o são - críticas, acabam por referendar a impraticabilidade de "qualquer concepção de ordem social radicalmente diferente daquela estabelecida" (MÉSZÁROS, 2004, p. 233, grifado no original). ${ }^{7}$

Se a conjuntura da própria crítica se coloca tais bloqueios de horizonte programático e se a estrutura de base político-ideológica-epistemológica historicamente constituída dos cursos de Direito ( $c f$. RODRIGUES, 2005) ainda mais corrói a resistência da crítica, a superestrutura acadêmica da educação jurídica no Brasil, em cima da qual os movimentos críticos concentravam prioritariamente esforços de inflexão, igualmente não abre margem suficiente para reformulações significativas dos cursos.

Sobre este aspecto, uma circunstância possível de apreensão objetiva das experiências da crítica da educação jurídica pode ser apontada na insuficiência das alterações gerais de nível regulatório e específicas dos cursos, no sentido do que destaca

\footnotetext{
5 Como bem esclarece Mészáros (2004, p. 233): “Além disso, dada sua posição privilegiada na ordem social prevalecente, elas [as ideologias dominantes] podem ditar as condições e regras gerais do próprio discurso ideológico. Isso acaba trazendo sérias consequências para os intelectuais que tentam articular alguma forma de contraconsciência, pois são obrigados a reagir às condições impostas, em um terreno escolhido por seus adversários".

6 Necessário apontar, entrementes, a autoproclamação este autor como um pós-moderno progressista, o que, de certa forma, reflete sua influência nos movimentos sociais e intelectuais das periferias, principalmente a latino-americana.

7 Uma caracterização sintética de parte significativa deste movimento teórico é feita por Baratta (1995, p. 121/122): “[...] uma parte representativa dos intelectuais do nosso tempo professa o abandono do assim chamado "pensamento forte" [...]. Trata-se de um pensamento que renuncia às grandes sistematizações teóricas, às grandes histórias, à grande luz, e que se contenta com pequenas verdades, com pequenas histórias, com sistematizações parciais e provisórias [...] [...] prevalecem o interesse e a capacidade de descrever a situação de nosso tempo, de realizar uma auto-reflexão inquieta e lúcida sobre nosso ser atirado num mundo que ele não tem possibilidade real de controlar, mas faltam o interesse e a capacidade de fundar os valores e o projeto ético-político destinados a mudar a situação e a construir uma sociedade mais justa e mais feliz?"
}

Em Debat: Rev. Dig., ISSNe 1980-3532, Florianópolis, n. 10, p. 19-34, jul-dez, 2013. 
Rodrigues (2005), ao comentar o equívoco de propostas alternativas centradas exclusivamente em alterações curriculares. Bem assim que as reformulações regulatórias (currículo e programa pedagógico) demonstraram não ser, por si só, ferramentas possíveis de emplacar, por mínima que fosse, uma alteração concreta nas caraterísticas privatistas/tecnicistas/conservadoras dos cursos. O que novamente reforça o lugar da crítica como conteúdo estranho da área.

Compreendendo-se isto sistematicamente com a caracterização geral da educação superior levantada no tópico 1 supra se pode ter uma noção dos desafios de criar, defender e praticar uma ação docente contra-ideológica no âmbito da educação jurídica hoje.

\section{Para além da negação: elementos para uma ação docente contra- ideológica}

Partindo da premissa de que as condicionantes levantadas até então tendem como é da sua lógica -, principalmente, a desencorajar, refluir e por fim acabar com iniciativas concretas de atuação contra-hegemônica e subversiva dos sujeitos comprometidos com uma ação docente nestes termos no âmbito da educação jurídica, parte-se agora para a abordagem de alguns elementos de reafirmação, para além de uma mera resistência retórica, teórica e acadêmica da crítica, da possibilidade uma ação docente superadora da mera negação da funcionalidade da educação jurídica para a ordem burguesa.

Isto porque, como adverte Mészáros (2008, p. 56)

Necessitamos, então, urgentemente, de uma atividade de "contra-
internalização", coerente e sustentada, que não se esgote na negação - não
importando quão necessário isso seja como uma fase nesse empreendimento
- e que defina seus objetivos fundamentais, como a criação de uma
alternativa abrangente concretamente sustentável ao que já existe. [...]

A transcrição obviamente se refere a um tipo de ação política que transcende os limites de alcance da ação docente, mas é precisamente este elemento que se entende aqui importante por em evidência: a necessidade de uma vinculação orgânica com um projeto alternativo de sociabilidade. Esta vinculação, ousa-se sustentar, é o que pode dar sentido a uma ação docente em suas possibilidades de contraposição ao processo de internalização e naturalização da ordem hegemônica por parte dos sujeitos em relação aos quais se dirige a prática educativa no sistema de educação formal. 
A lição básica marxiana de que "todas as formas de negação permanecem condicionadas pelo objeto de sua negação" (MÉSZÁROS, 2008, p. 60) é retomada no presente artigo no sentido de buscar um referencial a uma práxis docente no ensino do Direito que possa inseri-la concretamente e de maneira contributiva na dinâmica da luta de classes do modo como ela se expressa neste setor da educação formal.

Por certo as limitações intrínsecas e extrínsecas desta empreitada contrahegemônica, já bastante evidenciadas ao longo do texto, estão apreendidas em primeira conta. Como diz Mészáros (2008, p. 45), “[...] a educação formal não é a força ideologicamente primária que consolida o sistema do capital; tampouco ela é capaz de, por si só, fornecer uma alternativa emancipadora radical". No entanto, uma ação docente referenciada num projeto hegemônico alternativo pode, a mercê dos processos históricos de ascensão da classe dominada e suas lutas, compor a construção de uma nova direção moral da sociedade (GRAMSCI, 1989).

A contra-ideologia como conteúdo fundante da ação docente converte a si mesma em ideologia propriamente dita, constituída objetivamente pelo conjunto de valores e concepção de mundo que exsurgem da realidade de uma classe dominada e que põe em disputa, rivaliza, com a ideologia dominante e naturalizada, promovendo a negação prática da ordem estabelecida e legitimada por aquela. ${ }^{8}$ Esta contraconsciência que surge da classe dominada atua na apropriação das mediações que, integradas na totalidade, possam repercutir potencialmente as inversões que conduzem à superação da ordem estabelecida.

Para promover a realização pedagógica de uma ação docente assim caracterizada, por certo é necessária a habilidade dialética do docente de envolver os conteúdos abstratos e obrigatórios com a realidade concreta da vida do educando. Valerse de sua liberdade de ensinar garantida constitucionalmente na perspectiva de arrefecer a lógica tecnicista do ensino do Direito com uma abordagem que dê conta de correlacionar a abstração das formas jurídicas objeto de estudo com as relações materiais que ficam obnubiladas pelas ficções jurídicas. Neste sentido, um método de abordagem que muito tem a contribuir para uma ação docente contra-ideológica é o sociocultural, cujo principal expoente é Paulo Freire (MIZUKAMI, 1986).

8 Para uma concepção diversa de ideologia e igualmente de base marxista conferir IASI, Mauro Luis.

Ensaios sobre consciência e emancipação. São Paulo: Expressão Popular, 2011. 
Por certo que uma ação docente contra-ideológica deve buscar a superação os tradicionais vícios que constituem majoritariamente as práticas educativas dos docentes do ensino do Direito. Uma caracterização elementar do que não fazer encontramos na crítica ferina de Lyra Filho (1993), que, ao tipificar as concepções e práticas dos docentes conservadores, classifica-os em ceguinhos, catedr'áulicos ou nefelibatas. Se bem estas categorias se referem aos docentes conservadores, delas se lhes retira o necessário cuidado para que a ação docente contra-ideológica não seja por ela mesma igualmente manualesca, simplória e vazia de formulação; metodologicamente positivista, apenas substituindo códigos por teorias críticas; ou vulgarmente academicistas e abstracionistas.

Fazendo uma leitura de Miaille (2010), no texto em que promove um balanço de sua experiência na tentativa de promover um grito crítico no ensino da cadeira de Direito Constitucional, se extrai - particularmente para a problemática deste trabalho um elemento importante de inspiração para a construção de um outro tipo de prática docente: o ensino que se pretende crítico, referenciado em autores que melhor lograram esclarecer os movimentos essenciais de seus objetos de estudo, não pode se converter em puro dogmatismo. Neste sentido, pretende-se apontar aqui que um método de abordagem exclusivamente tradicional e bancário, por mais que preenchido de autores revolucionários, não tende a ser potencialmente uma ferramenta de libertação ideológica dos educandos, já que a dilui em simbologias sem uma respectiva assimilação dialética.

Ademais do cuidadoso reformular da abordagem do processo ensino/aprendizagem, é certo que se o recente projeto de fragmentação da universidade escamoteou a pesquisa e a extensão do quotidiano das instituições (como um dos corolários da formação minimalista e preservadora do ethos capitalista), uma ação docente contra-ideológica não pode se furtar de relegitimar estes dois elementos do tripé, fugindo, quanto ao primeiro, do cientificismo positivista e resistindo, quanto ao segundo, à política de cooptação que advém com a prática de editais para financiamento das atividades.

Essa circunstância oportunamente encerra outra tensão de consciência e práxis: a necessidade de o docente do Direito reconhecer-se enquanto trabalhador, o que implica, aquém da tarefa de auxiliar na construção de caminhos para a conquista das demandas históricas de sua classe - o que se vem tentando projetar centralmente até então -, na imperiosidade das demandas mais imediatas (econômicas e políticas) que revertam 
melhores condições de trabalho e, portanto, maior potencial de implementação de sua docência assim qualificada.

Por fim, é necessário frisar que os elementos suscitados quanto a possibilidade, legitimidade histórica e limites de uma ação docente nos termos em que se tentou delinear ao longo deste artigo não guardam a pretensão de conformarem uma plataforma mirabolantemente inovadora, taxativa e orientadora de uma ação docente pré-idealizada para a educação jurídica, mas tão somente a proposta de sistematizar, em exercício de síntese para novo envolvimento dialético, elementos conformadores de uma unidade de sentido para uma possível e diferente ação docente na educação jurídica.

\section{Conclusão}

$\mathrm{O}$ artigo que ora finda procurou apontar elementos para a conformação de uma ação docente contra-ideológica no espaço da educação jurídica brasileira. Para que tal proposta pudesse assumir pertinência histórica, partiu-se de uma primeira caracterização geral da educação superior, com o desvelamento político do movimento material e suas respectivas forças sociais que centralmente definem o modelo.

Determinada pelas mesmas lógicas que se expôs no primeiro momento, mas conformada por tensões e processos específicos, buscou-se um brevíssimo histórico periodicizado da formação jurídica no Brasil, desde a sua criação e chegando no seu perfil atual e no que este é produzido e logra produzir na totalidade social brasileira.

Partiu-se na sequência para o papel histórico da crítica da educação jurídica e para a compreensão de suas possibilidades e limites, projetando o quadro básico estrutural e conjuntural a partir do qual se sistematizou elementos para a construção, legitimidade e prática de uma ação docente contra-ideológica naquele âmbito.

A proposta de se pensar numa ação docente contra-ideológica deriva da apreensão do poder que a ideologia detém na conservação e reprodução do modo de produção e organização da sociedade com seu respectivo conjunto de ideias. Assim que se o poder de naturalização da ordem vigente e de obscurecimento das reais determinações que a mantém pode ser confrontado por meio da contraposição de um projeto de sociedade rival e radicalmente diferente, viu-se que há possibilidades limitadas e condicionadas de se projetar ao âmbito da educação jurídica a negação da primeira e a necessária defesa orgânica do segundo. 
Outrossim, a possibilidade e a necessidade de uma ação docente contraideológica na educação jurídica encontra um referencial desafiador nos recentes fenômenos que eclodem no Brasil ao tempo em que este artigo é formulado, com manifestações em todas as partes, principalmente nas capitais, em frequência quase que diária, numa expressão ainda incerta e sem direcionamento de um descontentamento historicamente acumulado, principalmente das classes exploradas.

Esta experiência recente abre um processo no qual a ação docente aqui defendida pode se inserir concretamente, refletindo empiricamente o que se tentou sustentar: na denúncia e negação da ordem que começa timidamente mas concretamente a ser questionada e com a consequente ajuda na formação de uma direção moral que possa disputar a hegemonia e lançar um projeto diferente; de outro modo, atuar de forma imediata, como resistência, por dentro do sistema ao qual o sujeito docente está inserido, na defesa de direitos e garantias sistematicamente violados em contextos de crise.

\section{Referências}

ASSOCIAÇÃO NACIONAL DOS DOCENTES DO ENSINO SUPERIOR SINDICATO NACIONAL. Dossiê Nacional 3. Brasília, 2013.

BARATTA, Alessandro. Ética e pós-modernidade. In: KOSOVSKI, Ester (org.). Ética na Comunicação. Rio de Janeiro: Editora Mauad, 1995, p. 113-131.

BARRETO, Raquel Goulart e LEHER, Roberto. Do discurso e das condicionalidades do Banco Mundial, a educação superior "emerge" terciária. Revista Brasileira de Educação. Rio de Janeiro: set./dez. 2008, v. 13, n. 39, p. 423-436.

CENSO DA EDUCAÇÃO SUPERIOR (2011), disponível em: $<$ http://download.inep.gov.br/educacao superior/censo superior/resumo tecnico/resum o tecnico censo educacao superior 2011.pdf> Acesso em 22 mar 2014.

GRAMSCI, Antonio. Os intelectuais e a organização da cultura. Rio de Janeiro: Civilização Brasileira, 1989.

LEHER, Roberto. Um Novo Senhor da educação? A política educacional do Banco Mundial para a periferia do capitalismo. Revista Outubro. São Paulo: out. 1999, v. 1, n. 3, p. 19-30. 
LYRA FILHO, Roberto. "Por que estudar Direito hoje?” In: SOUSA JR., José Geraldo (org). Introdução Crítica ao Direito. Brasília: UnB, 1993, 4ª ed., p. 22-27.

. "Para uma Visão Dialética do Direito". In: SOUTO, Cláudio e FALCÃO, Joaquim (org.). Sociologia e direito: textos básicos para a disciplina de sociologia jurídica. São Paulo: Pioneira, 1999, p. 71-78.

MATTOS, Marcelo Badaró. Reorganizando em meio ao refluxo: ensaios de intervenção sobre a classe trabalhadora no Brasil. Rio de Janeiro: Vício de Leitura, 2009.

MÉSZÁROS, István. O poder da ideologia. São Paulo: Boitempo, 2004.

. A educação para além do capital. São Paulo: Boitempo, 2008.

MIAILLE, Michel. "Ensinar o Direito Constitucional: a Crítica do Direito à Prova”. In: BELLO, Enzo (Org.) e LIMA, Martônio Mont'Alverne Barreto (Org.). Direito e Marxismo. Rio de Janeiro: Editora Lumen Juris, 2010, p. 317- 329.

MIZUKAMI, Maria da Graça Nicoletti. Ensino: as abordagens do processo. São Paulo: Editora Pedagógica e Universitária Ltda., 1986.

RODRIGUES, Horácio Wanderlei. Pensando o ensino do Direito no século XXI. Florianópolis: Fund. Boiteux, 2005.

WOLKMER, Antonio Carlos. História do Direito no Brasil. Rio de Janeiro: Forense, 2003. 